Copyright (C) 2017 American Scientific Publishers

All rights reserved

Printed in the United States of America
Advanced Science Letters

Vol. 23, 6256-6260, 2017

\title{
The Diversity of Birds and Frogs Species at Perdana Botanical Lake Garden, Kuala Lumpur, Malaysia
}

\author{
Zainul Mukrim Baharuddin*, Nadia Rusli, Lukman Ramli, Rashidi Othman, and Maheran Yaman \\ Landscape Ecology and Herbarium Unit, Department of Landscape Architecture, Kulliyyah of Architecture and \\ Environmental Design (KAED), International Islamic University Malaysia, Kuala Lumpur, Malaysia
}

\begin{abstract}
Unbalance urban development would affect the ecosystem and environment of the people and living things. Declining and loss of flora and fauna species occurs because of landscapes and living habitat changes. Urban biodiversity is a part of ecological elements and ecosystems services of the urban environments. Thus, it is important to be maintained or preserved in urban planning and design. The lack numbers of study focusing on the field of urban wildlife such as birds and frogs around the globe. Thus, the aim of the study is to understand the scientific data on urban wildlife mainly focus on birds and amphibian. This study will provide significant information pertaining to urban biodiversity issues. Birds is chosen as the best example that will act as an indicator for the inland environment while frogs as the amphibian for the urban lake garden. Birds can be the best indicator for inland environment while frogs can be indicator for the aquatic environment of the urban lake garden. The study was conducted at Perdana Botanical Lake Garden in Kuala Lumpur, Malaysia. The observation survey includes in details of the name of the species, number of species, habitat, data observation on time and dates, remarks and reference notes. The survey method on birds used the transect lines in order to observe the bird species within a measured line. The observation includes calculations and records of all the birds species, while walking along the transect route at average speed of $15 \mathrm{~m} / \mathrm{min}$ within $30 \mathrm{~m}$ distance. The survey usually conducted either early in the morning and late evening. Meanwhile, the amphibian observation on frogs survey based on 'Quadrant Sampling' which is the standard quadrant being set in metre $(\mathrm{m})$, in which $5 \times 5 \mathrm{~m}$ and $10 \times 10 \mathrm{~m}$. The amphibian observation begin during the night time for 3 days duration started from $7.00 \mathrm{pm}$ to $9.00 \mathrm{pm}$. Based on the observation at Botanical Perdana Garden, 8 species of birds has been identified. The most common is Acridotheres Tritis/Common Myna $(n=19)$ and the least is Geopelia Strata/Zebra Dove shows $(n=1)$ During the observation, a total of 6 species of frogs were found. The highest species of frogs recorded were Hylarana erythraea/Green Paddy Frog with $(n=80)$, while Fejervarya limnocharis/Indian Rice Frog $(n=1)$. The result concludes that the park need to have more species of birds that share the same eating diet such as frugivorous and nectarous. The lake garden should restructured especially the pond with ecological approach to attract more types of frogs.
\end{abstract}

Keywords: Urban Birds, Frogs, Urban Lake Habitat.

\section{INTRODUCTION}

Unbalance urban development would affect the healthy ecosystem and living environment of the people and living things. ${ }^{1,2}$ Declining and loss of flora and fauna species are dominantly occur because of land use changes. Most of African countries for example facing the declining of their ecosystem services due to conversion of green infrastructure to be-commercialization and industrial development. ${ }^{3}$ While the green spaces have been taken place, to rejuvenate it back in planning and design is a tremendous challenges that required understanding of the process, functions, stability and usability of interdisciplinary. ${ }^{4,5}$ In Islamic perspective have a wide theories to describe what is the meaning

*Author to whom correspondence should be addressed. of sustainable development and to maintain balance of the surrounding environment that envelope the triple bottom concept of sustainability in economy, social and environment. In Al Quran mentions, how to sustain the balance between the physical and spiritual functional. "The Most Merciful, Taught the Qur'an, Created man, [And] taught him eloquence, The sun and the moon [move] by precise calculation, And the stars and trees prostrate, And the heaven He raised and imposed the balance, That you not transgress within the balance, And establish weight in justice and do not make deficient the balance. And the earth He laid [out] for the creatures, Therein is fruit and palm trees having sheaths [of dates], And grain having husks and scented plants, So which of the favors of your Lord would you deny?. ${ }^{6}$ Thus it is vital for human to protect the balance of it living environment 
and to be thankful to Allah for all His precious hospitality for human to be able to living in prosperity.

\section{IMPORTANCE OF URBAN WILDLIFE IN CITIES}

The United Nations declared 2010 as the 'International Year of Biodiversity.' The biodiversity movement initiated many activities such as conferences and debates on world biodiversity. ${ }^{7}$ This movement has sought and promoted fresh commitments since the United Nations Conference on Environment and Development in Rio de Janeiro in 1992. There are various effort have been made by organization to promote the concept of urban ecology in cities. IALE for examples consistent organized platform of urban ecological knowledge discussion around the globe such as 8th AILE congress in Beijing and other congress such as URBIO conference 2014 "Cities and Water" in Songdo Incheon, Republic of Korea. From the conference several of ideas and techniques have been adapted and implement for the development. From the develop and developing countries, five dimension have been consider for future challenging in establishing urban ecology in to main stream of planning and urban design such as

(1) Stabilize and develop urban ecosystem services

(2) Planning approaches for sustainable urban environment

(3) Conservation of urban nature/biodiversity

(4) Interactions of urban environment and urban culture

(5) Climate change and adaptation. ${ }^{5}$

Malaysia has been strengthening conservation policies through the Convention on Biological Diversity 1994 with the vision of operating national policy over conservation programs. ${ }^{8}$ However, more commitment is needed to be undertake by Malaysian local and private agencies towards understanding of the application on urban ecology for sustainable urban environment. For instance, the capital city of Kuala Lumpur, aim in the coming future to be known as 'Sustainable Tropical garden City by 2020' and have been emphasizing the enhancement of the green and blue corridors.

Urban design and planning of urban areas face greater challenges and play an important role in the protection and conservation of urban biodiversity. ${ }^{9,} 10$ The awareness of conservation is important to fulfill physical and social needs as cities grow rapidly. The aim of this study is to observe population of avian and amphibian can be as indicator for healthy ecological environment in urban park such as Perdana Lake Garden in Kuala Lumpur, Malaysia.

\section{METHODS}

The study was conducted at Perdana Botanical Lake Garden in Kuala Lumpur, Malaysia. Established in the 18th century known as the 'green lung' for Kuala Lumpur. Perdana Lake Garden is a famous spot for tourist attractions. The park is located on the hill in the heart of the city of Kuala Lumpur. It is surrounded by national institutions such as Police Headquarters, National Mosque, Islamic Museum and many more. It is also divided into sub-gardens such as the Hibiscus Garden, Bird parks, National monuments and the Lake Garden. The land of the park covered around 70 hectares and is famous for city park which can accommodate around 50,000 visitors. The observation area was concentrated at the Lake Garden where it is used as public space.
Most of the vegetation here is mature and massive. It provides natural shade for the park and relaxing environments for leisure and recreation activities.

\subsection{BIRD SURVEY}

A transect techniques was implemented inspired from Buckland, ${ }^{11}$ for the birds observation in Perdana Botanical Lake Garden. The bird survey was conducted early in the morning and late evening. It was the ideal time where the birds actively out to gather for food and back to their nest. The bird survey will calculate and records all the birds species observed along the transect route. Data based on the observations includes the species name, number of species, habitat, time and date, remarks and reference notes will be collected/gathered. The average speed of $15 \mathrm{~m} / \mathrm{min}$ within $30 \mathrm{~m}$ distances which accessible along the park. The park was subdivided into 2 transects to observe birds within a measured line.

The survey recorded the species name, number of species, habitat, observation time and date, remarks and reference notes. The bird surveys were conducted to understand the relationship between people's perceptions and scientific data on urban wildlife that could provide significance information pertaining to urban biodiversity issues. The survey that has been conducted through the transect lines to observe bird species within a measured line in the park. The observer will calculate all the birds and records all the birds, sound, activities, routines along the transect route at average speed of $15 \mathrm{~m} / \mathrm{min}$ within $30 \mathrm{~m}$ distance. All the transects will be visited multiple times in a year. This transect technique was adapted or inspired by Buckland. ${ }^{11}$

\subsection{AMPHIBIAN SURVEY}

Although amphibian can possibly be found throughout the park, this research scope specifically focus on wetlands areas at the

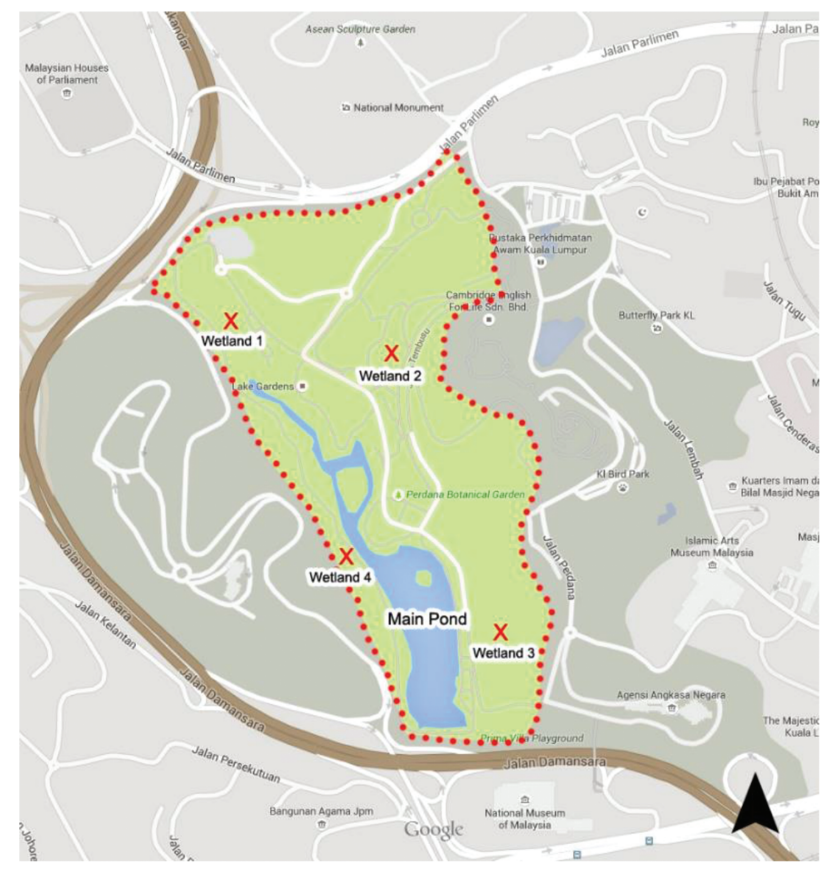

Fig. 1. The location of the wetlands that being assessed for amphibian survey. 
park. ${ }^{12}$ According to aquatic amphibian survey protocol, ${ }^{12}$ this selection of sites considered as a complete survey which can avoid biases in selecting the sites. The selection is relevant because Perdana Botanical Garden area can be access within an hour.

Secondly, all four wetlands being divided into several parts to ease the data analysis. The division made based on a few characteristic that might become a manipulative variables number of amphibian. For this survey two methods were used namely "basic technique" and "visual searches"12 which require manually scanning of basking frogs, tadpoles and their eggs near the water bodies. For this technique CREE XML-T6 LED flashlight was used as it emitted cold white colour with high intensity.

The calculation for the types of amphibian, the technique used was 'Quadrant Sampling,' the standard quadrant being set in metre $(\mathrm{m})$, in which $5 \times 5 \mathrm{~m}$ and $10 \times 10 \mathrm{~m}$ are the measurement used. Wetland 1,3 and 4 were using $5 \times 5 \mathrm{~m}$ quadrant, while $10 \times 10$ for Wetland 2 because it is relatively bigger than all other wetlands.

Accessing amphibian begin at night, within estimated 3 days duration started from $7.00 \mathrm{pm}$ to $9.00 \mathrm{pm}$. The sessions conducted at night because it is the most suitable time as the amphibian cab can be observe closely from its hidden habitat. The Type of amphibian species, stage of growth and the number of amphibian found were recorded on respective map of four wetland being drawn previously. Symbol were formed as indicator to differentiate the type of amphibian found. A high performance torchlight being used as aided tool for night vision and to distanced amphibian and netting being use to capture unique amphibian species (if found available). Camera being used to capture the image of amphibian found for species identification process later.

Some amphibian cannot be reach by naked eyes and might not been seen, but the sounds still can be heard clearly. Thus, sound recording method being used to calculate the number of amphibian. The voice identification will be conducted by experts in Malaysia and the number of amphibian at one time record being counted approximately. The data obtained will be analysed processed in table using Microsoft Excel.

\section{EXPERIMENTAL RESULT}

As can be seen in Table I, 36 numbers of birds were found and recorded around eight different type of species. The transect lines concentrated near to the lakeside because it is near to the water source as it is vital for the growth and survival of the bird. Based on the observation at Perdana Botanical Lake Garden, 8 species of birds has been identified within two different transect lines. The most common bird in the city which has been identified is Acridotheres tritis (Common Myna) $(n=19)$, while Geopelia strata (Zebra Dove) indicate lowest numbers of species observed. Common Myna have a rich, glossy black head and neck while legs and feet are waxy yellow. Often found within its group on the ground. This bird are quite brave and love to get close to human and take food on the ground. In comparison, Zebra Dove or commonly dove species are found especially in the evening. They love sheltering in the shade of the leaves. Often seen in small parties or pair. They will fly off when disturbed and hide among the leaves again. Compared to Spotted Dove, this kind of bird species is fairly common. Furthermore, other bird species identified were Halcyon. smyrnensis (White-Throated Kingfisher) $(n=4)$ known as native and protected species, Oriolus chinensis
Table I. The species and number of birds that can be founded in Perdana botanical garden.

\begin{tabular}{lr}
\hline Species & Tota \\
\hline Halcyon smyrnensis (W.-T. Kingfisher) & 4 \\
Oriolus chinensis (Blacked Naped Oriole) & 3 \\
Merops apiaster (Europian Bee-Eater) & 2 \\
Sreptopelia chinensis (Spotted Dove) & 2 \\
Geopelia striata (Zebra Dove) & 1 \\
Acridotheres tritis (Common myna) & 19 \\
Nycticorax nycticorax (Black-Crowned Night-Heron) & 2 \\
Copsychus saularis (Oriental Magpie Robin) & 3
\end{tabular}

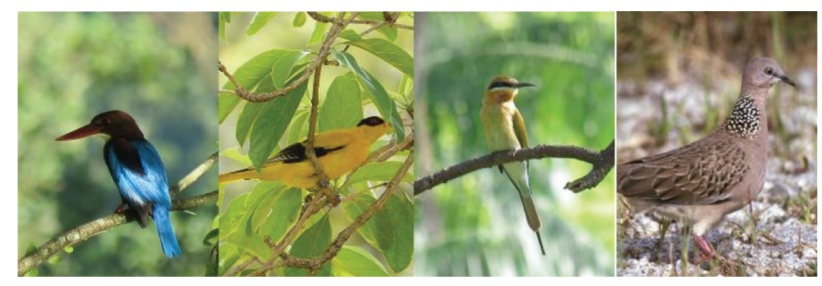

(Above from left) Halcyon smyrnensis, Oriolus chinensis, Merops apiaster, Sreptopelia chinensis.

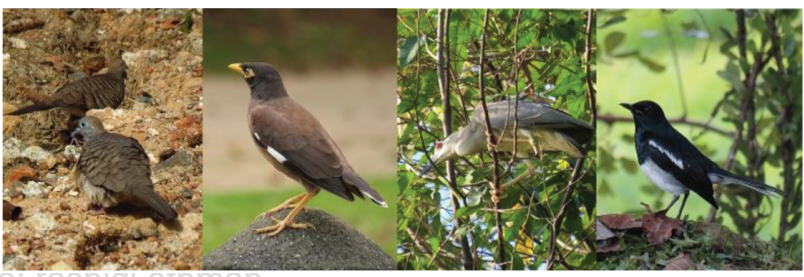

(Below from left) Geopelia striata, Acridotheres tritis, Nycticorax nycticorax, Copsychus saularis. hers

(Blacked-Naped Oriole) $(n=3)$ and Copsychus saularis (Oriental Magpie Robin) $(n=3)$. The Black-Naped Oriole are not found everywhere but they are usually in pairs. They are quietly hard to be captured as they flit among the branches of a tall tree. During the observation the number of birds least found are Merops apiaster (Europian Bee-eater) $(n=2)$, Streptopelia chinensis (Spotted-dove) $(n=2)$, and Nycticorax nycticorax (BlackCrowned Night Heron) $(n=2)$. In contrary, Magpie robin are quite unafraid of man and the nest are built not far from the ground. While the Night Heron spends most of its time in most inaccessible swamp area. Thus, it's quite hard to be seen and recorded during the survey.

\subsection{SPECIES OF AMPHIBIAN}

Throughout the findings, variety of species found in different stages of amphibian life cycles includes Duttaphrynus melanostictus (Common Sunda Toad), Hylarana erythraea (Green Paddy Frog), Polypedates leucomystax (Four-line Tree Frog), Fejervarya cancrivora (Crab-eating Frog), Microphyla fissipes (Ornate Narrow-mouthed Frog) and Fejervarya limnocharis (Indian Rice Frog). Those were found as in the frog's life cycle stages such as eggs, juvenile and adult. The main species found Hylarana erythraea with $(n=80)$ abundantly found at Wetland 2, while other species were recorded with less than 10 number per species, consist of Duttaphrynus melanostictus $(n=5)$, Polypedates leucomystax $(n=3)$, Fejervarya cancrivora $(n=2)$, Microphyla fissipes $(n=7)$ and Fejervarya limnocharis $(n=1)$. There were few 
Table II. The species and number of amphibians that can be founded in perdana botanical garden.

\begin{tabular}{lccccr}
\hline Species & W. 1 & W. 2 & W. 3 & W. 4 & Total \\
\hline D. melanostictus & 0 & 0 & 5 & 0 & 5 \\
H. erythraea & 0 & 12 & 68 & 0 & 80 \\
P. leucomystax & 0 & 1 & 2 & 0 & 3 \\
F. cancrivora & 0 & 2 & 0 & 0 & 2 \\
M. fissipes & 0 & 0 & 7 & 0 & 7 \\
F. limnocharis & 0 & 1 & 0 & 0 & 1 \\
Juvenile frog & 0 & 1 & 2 & 0 & 3 \\
Frog's egg (clump) & 0 & 0 & 2 & 0 & 2 \\
Unidentify & 0 & 0 & 0 & 1 & 1 \\
\hline
\end{tabular}

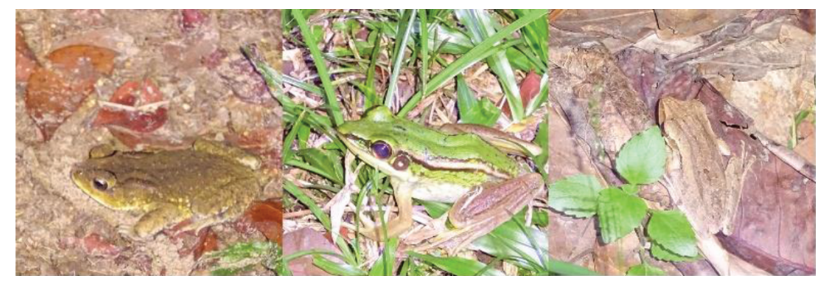

(Above from left) Duttaphrynus melanostictus, Hylarana erythraea, Polypedates leucomystax.

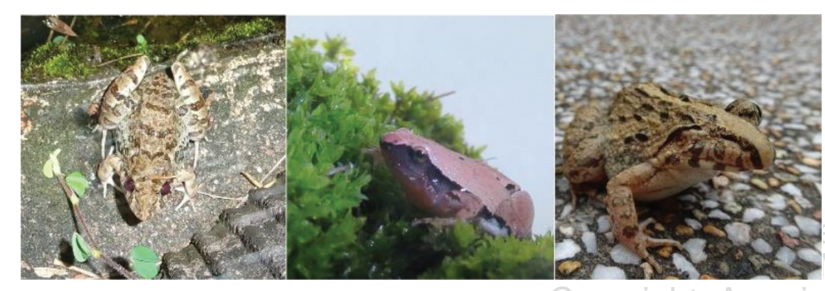

(Below from left) Fejervarya cancrivora, Microphyla fissipes, Fejervarya limnocharis.

findings of other morphological type, which are 'unidentified' species recorded at Wetland $4,(n=2)$ amphibian's egg clump found at Wetland 3 while $(n=3)$ of juvenile frogs found at Wetland 2 and 3.

From the overall survey, only one types of frogs were detected having some abnormality. The frog is known as Fejervarya limnocharis which the natural habitat is located at wetland 2 . The malformation of this frog also known as microphthalmia or missing eye. ${ }^{13}$ However, this frog were found in adult stages and the exact cause of the abnormality remain unknown. This frog maybe exposed to harmful pollution or humans or accidentally from nature causes such as a fail predator attempt. ${ }^{13}$ Although this data may not significance due to less than $5 \%$ occurrence, it is a clear sign for further data collection to survey malformed frogs. ${ }^{13}$

\section{CONCLUSIONS}

The Botanical Perdana Lake Garden, Kuala Lumpur is vital as it provides natural ecological functions and ecosystem services towards the urban biodiversity. There are many types of birds and amphibian species can be found here even though it is surrounded by city. There are seven protected bird species found in the area and but only one birds like common myna can be found here. This shows that patches of green spaces is significant to contribute a place for urban wildlife habitat. Furthermore,
Miller ${ }^{14}$ in her study indicate that green patch such private garden may provide habitat and food resources for urban birds.

Study on birds is valuable in estimating the increase and decrease of bird populations. If one can identify species that are particularly vulnerable to habitat loss or change, it may be possible to prevent them becoming threatened. Modification of natural habitat for development reasons takes a variety of forms. However, the largest numbers of bird species found in Perdana Lake Garden, Common Myna are among the frequently seen in parks and gardens. It is well known as aggressive and determined breeders in many places. Common Myna love to nest high above the ground such houses in the city. They are most likely to be found because Myna loves to spend most of the time at ground. In other hand, other species of birds such as White-Throated Kingfisher, Black Naped Oriole and Spotted Dove are also found in park and gardens. Nonetheless, some of the species love to flit among the branches of a tall tree ${ }^{15}$ and normally common found near the sea while Spotted Dove prefer lower ground of some bushy shrub and small tree. Thus, one of the factors to create a diverse biodiversity of a park, is to have natural water source and various types of plants that will attract more species of birds to come. It also crucial to identify the birds daily diet and consumption to create a diversity of bird species in the urban park..$^{15}$ As the birds found in the park are mostly recognized as among granivorous diet consist of seed such as Spotted Dove, insectivorous diet consist of insects or lizards such as Common Myna and Throated Kingfisher. Hence, more improvement needed for the habitat conservation and restoration. Thus, it is much recommended if the urban park can provide more plant species to promote types of birds which associate with diet such as frugivorous and nectarous. ${ }^{16} /$ Miller $^{14}$ have present that nectar-eating birds have increase in urbanization area which have potential resources.

From the result obtained, it is concluded that amphibian could be the best indicator for changes happen in aquatic layout of urban park. ${ }^{17}$ It can be of the strong factor to encourage the diversity of amphibian in park, with different functions and abilities. Reflecting to the favorable habitat of the amphibian, the researcher shall consider design guideline of ecological approach $^{5}$ edge to encourage this expansion. ${ }^{18}$ The species of 'green corridor,' for instance, shall be implemented in design guideline, instead of materials selections while doing embankment design. In other hands, the height, linkages and density of the edge will be important for amphibian movement from one point to another as their dispersal ability is limited in urban area. ${ }^{19}$

As amphibian love to be in wet and watery place, the design shall implement more on water retention design as preparation when facing the changing climate that could kill the species. ${ }^{18}$ Human intervention on amphibian habitat also shall be reduced, in which the heavy access of human shall be distanced with the amphibian habitat to preserve the species.

Acknowledgments: The authors would like to thank, Ministry of Higher Education (MOHE) and International Islamic University Malaysia (IIUM) for the Research Grant FRGS13-012-0253 and RAGS14-043-0106.

\section{References and Notes}

1. C. Brown and M. Grant, Built Environ. 31, 326 (2005).

2. S. Idilfitri and N. H. N. Mohamad, Procedia-Soc. Behav. Sci. 68, 894 (2012). 
3. R. B. Primack, Essentials of Conservation Biology Fourth edition, Sinauer Associates (2006).

4. D. Saenz, T. L. Hall, and M. A. Kwiatkowski, Urban Ecosyst. 18, 333 (2014).

5. J. Breuste, S. Qureshi, and J. Li, Urban Ecosyst. 16, 675 (2013).

6. The Holy Quran, al-Baqarah, 2:11, Tafsir Pimpinan Ar- Rahman, Department of Islamic Development Malaysia, DarulFikir, Kuala Lumpur, Malaysia (2013).

7. The International Year of Biodiversity, Convention on Biogical Diversity (n.d), Available: https://www.cbd.int/2010/about/, Accessed on March 2016.

8. Ministry of Natural Resouces and Environment of Malaysia, Malaysia's 5th National Report to Convention on Biological Diversity (2014).

9. S. Qureshi, J. H. Breuste, and S. J. Lindley, Hum. Ecol. 38, 283 (2010)

10. R. F. Young, Urban Ecosyst. 12, 311 (2009).

11. S. T. Buckland, Auk 123, 345 (2006).
12. G. M. Fellers and K. L. Freel, A Standardized Protocol for Surveying Aquatic Amphibians (1995)

13. M. Lannoo, Malfomed Frogs; The Collapse of Aquatic Ecosystems, University of California Press, Ltd., London, England (2008), Vol. 53.

14. G. P. Cleary, H. Parsons, A. Davis, B. R. Coleman, D. N. Jones, K. K. Miller, and M. A. Weston, PLoS One 11 (2016).

15. S. Idilfitri, S. Sulaiman, and N. S. Salleh, Procedia-Soc. Behav. Sci. 153, 666 (2014).

16. A. Davis, R. E. Major, and C. E. Taylor, Urban Ecosyst. 18, 503 (2015)

17. E. Simon, M. Puky, M. Braun, and B. Tóthmérész, Frogs Biol. Ecol. Uses (2011)

18. A. J. Hamer and K. M. Parris, Ecol. Appl. 21, 378 (2011).

19. D. M. Marsh and P. C. Trenham, Conserv. Biol. 15, 40 (2001).

Received: 30 April 2016. Accepted: 30 October 2016. 